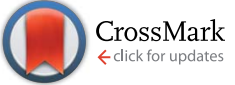

Cite this: RSC Adv., 2017, 7, 3823

\title{
Direct reuse of two deep-dewatered sludge cakes without a solidifying agent as landfill cover: geotechnical properties and heavy metal leaching characteristics $\dagger$
}

\begin{abstract}
Jiakuan Yang, ${ }^{\star a b}$ Shinan Zhang, ${ }^{a}$ Yafei Shi, ${ }^{\star a c}$ Chao Li, ${ }^{a}$ Wenbo $\mathrm{Yu}{ }^{a}$ Ruonan Guan, ${ }^{a}$ Jun Xiao, ${ }^{a}$ Sha Liang, ${ }^{a}$ Jingping $\mathrm{Hu}{ }^{a}$ Huijie $\mathrm{Hou}^{\mathrm{a}}$ and Jiukun $\mathrm{Hu}^{\mathrm{d}}$

Two types of deep-dewatered sewage sludge cakes were produced from pilot-scale experiments by using two composite conditioners: $\mathrm{FeCl}_{3}+$ quick lime (Fe-Lime) and Fenton's reagent + red mud (Fenton-RM). The feasibility of direct reuse without any solidifying agents of these two deep-dewatered cakes, with water content of about $60 \mathrm{wt} \%$, as landfill cover materials was investigated. Geotechnical properties of these two sludge cakes were found appropriate for reuse as landfill covers. Their plasticity index values increased significantly from 11.6 (raw sludge) to 23.8 (Fe-Lime) and 35.4 (Fenton-RM). The unconfined compressive strength and direct shear strength of the two deep-dewatered sludge cakes could meet or exceed the requirement of landfill cover materials after a certain curing time. Microstructural analyses of scanning electron microscopy (SEM) and X-ray diffraction (XRD) showed that their microstructures were more porous than that of raw sludge since the skeleton builders played a role in building the rigorous framework. There was negligible leaching of $\mathrm{Cu}, \mathrm{Zn}, \mathrm{Pb}, \mathrm{Cd}$ and $\mathrm{Cr}$ from the deep-dewatered sludge cake from the toxicity characteristic leaching procedure and column leaching test. Both deepdewatered sludge cakes could be reused as effective landfill cover materials with a suitable curing time.
\end{abstract}

Received 8th November 2016 Accepted 28th November 2016

DOI: $10.1039 / c 6 r a 26480 h$

www.rsc.org/advances about $75-85$ wt $\%$ with chemical conditioning with polymers (e.g., polyacrylamide (PAM)). To reduce the high water content of dewatered sludge so that it can be beneficially reused as a landfill cover material, three approaches are often taken. The first approach is sludge drying, ${ }^{5}$ which is extremely expensive and energy-consuming with a risk of emissions of unpleasant odors. The second approach is blending the dewatered sludge cake with soil. However, the proper type of soil is often not readily available. The third approach is to add solidifying agents into the dewatered sludge cake. With addition of solidifying agents such as Portland cement, ${ }^{6}$ fluidized bed combustion ash, ${ }^{7}$ converter slag, ${ }^{8}$ fly ash and lime, ${ }^{9}$ calcined aluminum salts, ${ }^{1}$ or magnesium oxychloride cement, ${ }^{10}$ the solidified sewage sludge specimens were found effective as landfill cover materials. Unfortunately, the mass ratio of the soil or solidifying agents to the dry solid of the dewatered sludge often needs to be $100-200 \%$. Consequently, the increased volume would take away lots of valuable landfill capacity. Direct reuse of dewatered sewage sludge as landfill cover materials without any soil or solidifying agents is seldom reported in literature. ${ }^{11}$

For landfill disposal, water content of sludge should be low; and the maximum water content limit is normally $60 \mathrm{wt} \%$ in China. ${ }^{12}$ Many attempts have been made to improve sludge dewatering by employing pretreatment. The pretreatment methods include physical and thermal processes, ${ }^{13,14}$ chemical

\footnotetext{
School of Environmental Science and Engineering, Huazhong University of Science yfshi@hust.edu.cn; Fax: +86 27 87792101; Tel: +86 2787792102

${ }^{b}$ State Key Laboratory of Coal Combustion, Huazhong University of Science and Technology, Wuhan, Hubei, 430074, P. R. China

${ }^{c}$ School of Civil Engineering, Architecture and Environment, Hubei University of Technology, Wuhan 430068, Hubei, P. R. China

${ }^{d}$ Dongjiang Environmental Co., Ltd., Shenzhen, Guangdong, 518057, P. R. China

$\dagger$ Electronic supplementary information (ESI) available. See DOI: $10.1039 / \mathrm{c} 6 \mathrm{ra} 26480 \mathrm{~h}$
} 
processes, ${ }^{15}$ and biological processes. ${ }^{16}$ Deep dewatering of sewage sludge using new types of chemical conditioners instead of the traditional polymer conditioners, have been extensively investigated and considered as a cost-effective alternative. In deep dewatering, water content of the dewatered sludge cake could be less than $60 \mathrm{wt} \%$, which makes it more suitable for subsequent reuses or disposal. $\mathrm{FeCl}_{3}$ combined with quick lime (referred as Fe-Lime) is a typical conditioner recommended by U.S. EPA in sewage sludge dewatering. ${ }^{17}$ In a Fe-Lime system, $\mathrm{Fe}^{3+}$ acts as a coagulant to provide polyvalent cations, and lime plays as a skeleton builder. ${ }^{18-20}$ Recently, an innovative composite conditioner of combined Fenton's reagent and red mud (referred as Fenton-RM) has been studied by this research group. ${ }^{21}$ In Fenton-RM system, Fenton reagent acts as an oxidant which destroys the extracellular polymeric substances structure and improves the release of the bond water in sewage sludge; while red mud (RM) plays as a skeleton builder to promote a rigid and permeable structure of dewatered sludge that improves sludge compressibility. In these two conditioning systems, skeleton builders (quick lime and RM) were added during dewatering so that they could be homogeneously dispersed into the dewatered sludge. The skeleton builders also play an important role in the subsequent solidification/ stabilization stage for the dewatered sewage sludge. By using either of these two systems, the water content of the treated sludge can be reduced to less than $60 \mathrm{wt} \%$.

In the previous paper, ${ }^{22}$ pilot-scale sewage sludge dewatering experiments were conducted using both composite conditioners: Fe-Lime and Fenton-RM. Consequently, two types of deep-dewatered sewage sludge cakes were obtained with water content of 52.8 and $47.7 \mathrm{wt} \%$, respectively. It was found that most of the heavy metals in sewage sludge were retained in the dewatered sludge cake. ${ }^{22}$ However, feasibility of direct reuse of

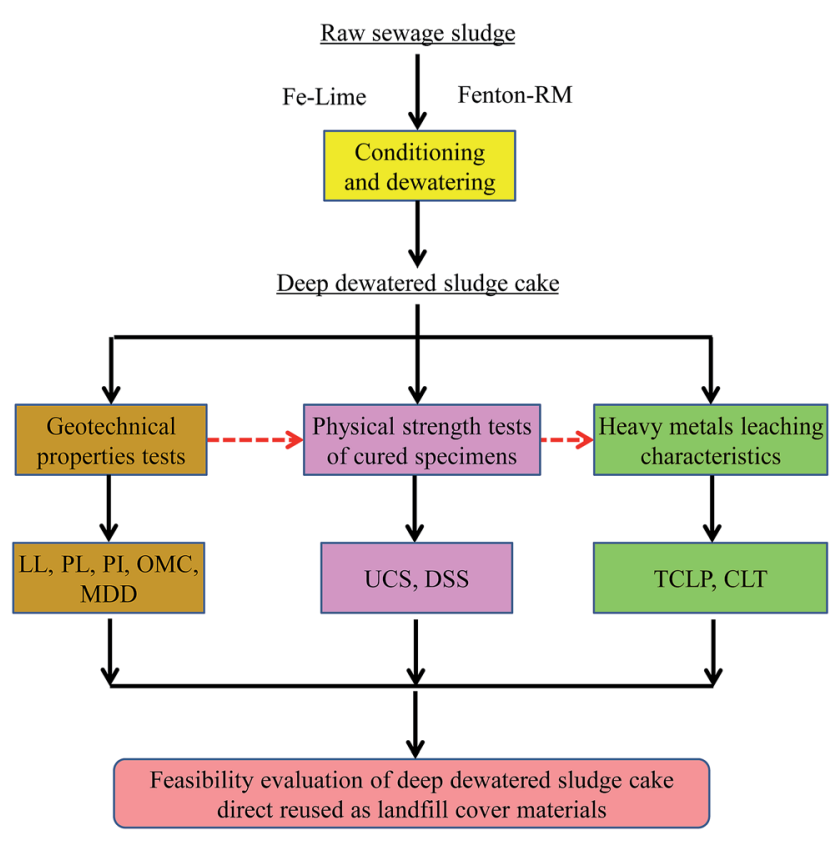

Fig. 1 Schematic of this study. those two deep-dewatered sewage sludge cakes as landfill cover materials has not been fully investigated.

The objective of this study was to evaluate geotechnical properties and heavy metal leaching characteristics of these two deep-dewatered sludge cakes. Two issues would be further investigated in this study: (1) how the skeleton builders would behave to improve the geotechnical properties of sludge cakes; (2) what are the leaching behaviors of heavy metals retained in the sludge cakes. Finally, feasibility of direct reuse of them as landfill cover materials would also be evaluated. The schematic of this study is depicted in Fig. 1.

\section{Materials and methods}

\subsection{Materials}

The raw sludge (RS) used in this study was a mixture of primary and secondary sludge after a gravity-thickening process from Tangxunhu WWTP in Wuhan, China. Table 1 summarizes some main characteristics of the RS sample. Two batches of RS were investigated in this study. RS-I was sampled in September of 2013; RS-II was sampled in April of 2014.

As presented in Table 1, the volatile suspended solid/total suspended solid (VSS/TSS) of RS-II is higher than that of RS-I since different influent load of sewage mixing with rainwater in various seasons. In the following experiments, RS-I was used in geotechnical tests, and both RS-I and RS-II were used in the leaching properties tests. Both RS samples had a $\mathrm{pH}$ close to neutral, and the concentrations of heavy metals $(\mathrm{Cu}, \mathrm{Zn}, \mathrm{Pb}, \mathrm{Cd}$ and $\mathrm{Cr}$ ) are in the order of $\mathrm{Zn}>\mathrm{Cu}>\mathrm{Cr}>\mathrm{Pb}>\mathrm{Cd}$.

$\mathrm{FeCl}_{3}, \mathrm{FeSO}_{4} \cdot 7 \mathrm{H}_{2} \mathrm{O}$ and $\mathrm{H}_{2} \mathrm{O}_{2}(27.5 \% \mathrm{v} / \mathrm{v})$ of industrial grade were obtained from a commercial company in China. $\mathrm{H}_{2} \mathrm{SO}_{4}$ was used to adjust the initial $\mathrm{pH}$ of the RS samples to the optimal value of 5.0 before the addition of Fenton's reagent. ${ }^{20}$ All the acids (including $\mathrm{H}_{2} \mathrm{SO}_{4}, \mathrm{HNO}_{3}, \mathrm{HF}$ and $\mathrm{HClO}_{4}$ ) used for sludge sample digestion were of analytical grade.

Quick lime and RM, which were used as skeleton builders, were dried, milled and sieved to less than $1 \mathrm{~mm}$ in particle size before use. The quick lime was obtained from a local factory. The RM was supplied by an alumina plant employing the Bayer process in Zhengzhou, China. Their chemical compositions are presented in Table S1 as ESI. $\dagger$

\subsection{Dewatering process and dewatered sludge cake}

Two composite conditioning systems (Fe-Lime and Fenton$\mathrm{RM}$ ) were used in this study. The sludge conditioning and dewatering process is presented in Fig. S1, $\dagger$ studied in our previous study. ${ }^{22}$ The scheme of sludge conditioning has been optimized in our previous work and is presented in Table S2. $\dagger^{21,23}$ After conditioning, the sludge was dewatered by a pilotscale diaphragm filter press in the Tangxunhu WWTP (Fig. 2). For each batch, 500-800 kg of RS was pumped into a conditioning tank. A more detailed description of the dewatering process was depicted elsewhere. ${ }^{22}$

Main characteristics of two types of deep-dewatered sludge cakes are presented in Table 2. After the deep-dewatering process, the water contents of the dewatered sludge cakes 
Table 1 Some basic characteristics and the concentrations of main heavy metals of the raw sludge samples ${ }^{a}$

\begin{tabular}{|c|c|c|c|c|c|c|c|c|}
\hline Batch & $\mathrm{pH}$ & Water content (wt\%) & VSS/TSS (\%) & $\mathrm{Cu}\left(\mathrm{mg} \mathrm{kg}^{-1}\right)^{*}$ & $\mathrm{Zn}\left(\mathrm{mg} \mathrm{kg}^{-1}\right)^{*}$ & $\mathrm{~Pb}\left(\mathrm{mg} \mathrm{kg}^{-1}\right)^{*}$ & $\mathrm{Cd}\left(\mathrm{mg} \mathrm{kg}^{-1}\right)^{*}$ & $\mathrm{Cr}\left(\mathrm{mg} \mathrm{kg}^{-1}\right)^{*}$ \\
\hline S-I & 7.2 & $96.0 \pm 0.1$ & $41.3 \pm 0.3$ & $132.1 \pm 2.9$ & $279.6 \pm 12.9$ & $.8 \pm 0.5$ & $4.5 \pm$ & $73.3 \pm 0.9$ \\
\hline RS-II & 6.9 & $96.9 \pm 0.1$ & $59.6 \pm 0.2$ & $192.0 \pm 2.0$ & $1139.3 \pm 10.3$ & $23.3 \pm 0.3$ & $2.9 \pm 0.1$ & $66.7 \pm 0.6$ \\
\hline
\end{tabular}

${ }^{a}$ On the dry solid basis. * Milligrams per kilogram of dry solid $\left(\mathrm{mg} \mathrm{kg}^{-1}\right)$.

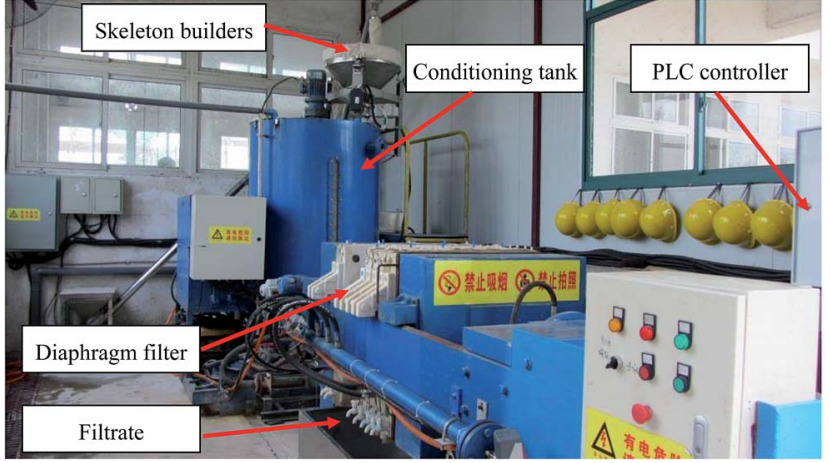

Fig. 2 The photo of the pilot-scale facility for sewage sludge conditioning and deep dewatering in the Tangxunhu WWTP.

from both systems were reduced to less than $60 \mathrm{wt} \%$, which is favorable for subsequent disposal, especially for landfilling. VSS/TSS ratios also decreased due to the addition of inorganic skeleton builders. As reported earlier, most of the heavy metals remained in the sludge cake during the dewatering process. ${ }^{22}$

The traditional dewatered sludge after conditioned with PAM (referred to RS-PAM) was comparatively investigated in the geotechnical tests. RS-PAM was produced from a centrifugal dewatering process after conditioning with PAM in the Tangxunhu WWTP. The water content of RS-PAM is $81.7 \mathrm{wt} \%$, and its $\mathrm{VSS} / \mathrm{TSS}$ is about $41 \mathrm{wt} \%$, which is almost the same as that of the RS-I sample.

\subsection{Geotechnical tests}

The dewatered sludge cakes were divided into two parts; one was tested for the geotechnical properties, and the other was used for mechanical strength tests. Geotechnical properties of the dewatered cakes from two composite conditioning systems (Fe-Lime and Fenton-RM) were compared to RS-PAM and standard clay specimen which was provided by Hubei Province Geological Experiment Institute, China.
The geotechnical tests for the samples were conducted in accordance with the Chinese standards for soil laboratory test methods (GB/T 50123-1999) for water content, liquid limit (LL), plastic limit (PL) and plasticity index (PI). ${ }^{24}$ The classification of the solidified sludge was determined in accordance with the Unified Soil Classification System. ${ }^{25}$ The dewatered sludge specimens were molded in a self-made compactor device to determine the optimum moisture content (OMC) and the maximum dry density (MDD). A heavy compaction procedure (5 layers, 27 times compaction for each layer), as specified in Chinese test methods of soils for highway engineering, was used to estimate the characteristics of compaction. ${ }^{26}$ The permeability of the dewatered sludge specimens under optimum compacted conditions was also measured by a variable-head permeability test following the Chinese standard. ${ }^{24}$

Mechanical strength properties, i.e., unconfined compressive strength (UCS) and direct shear strength (DSS), were also determined according to the standard. ${ }^{24}$ The cylinder specimens for the UCS test were $3.91 \mathrm{~cm}$ in diameter and $8.0 \mathrm{~cm}$ in length, and the ones for the DSS test were $6.18 \mathrm{~cm}$ in diameter and $2.0 \mathrm{~cm}$ in length with a relative compaction of $90 \%$. The specimens were cured in a standard curing chamber at $20 \pm$ $2{ }^{\circ} \mathrm{C}$ with humidity $>90 \mathrm{wt} \%$. Triplicate samples were immersed in water for $24 \mathrm{~h}$, and used to evaluate the mechanical strengths of these specimens cured for $0,3,7,14,21,28,60,90$ days.

\subsection{Leaching tests of heavy metals}

The leaching tests for heavy metals were performed according to two specifications: a standard toxicity characteristic leaching procedure (TCLP) as a short-term leaching test and a column leaching test (CLT) for the long-term leaching characteristics. In the Fe-Lime system, the dewatered sludge cake of Fe-Lime-I was investigated on leaching tests for heavy metals, and RS-I was studied as a control. In Fenton-RM system, the dewatered sludge cake of Fenton-RM-II was investigated on leaching tests for heavy metals, and RS-II was studied as a control.

Table 2 Main characteristics of the dewatered sludge cakes ${ }^{a}$

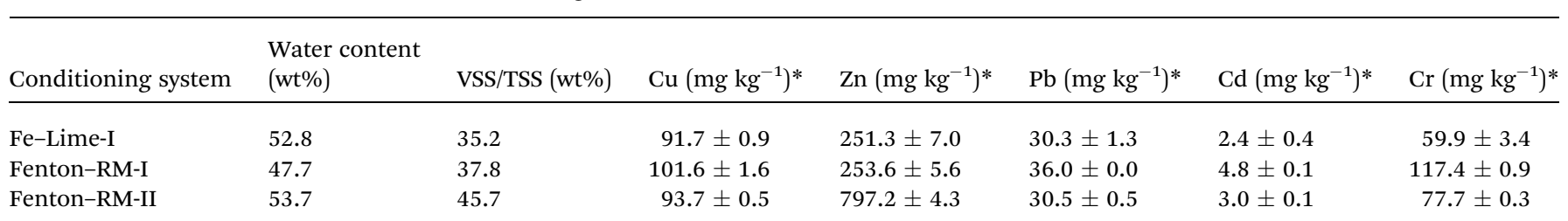

${ }^{a}$ On the dry solid basis. ${ }^{*}$ Milligrams per kilogram of dry solid $\left(\mathrm{mg} \mathrm{kg}^{-1}\right)$. 
According to TCLP, ${ }^{27} 50 \mathrm{~g}$ air-dried sludge specimens (FeLime-I and RS-I) was grinded and sieved to achieve particle sizes smaller than $9.5 \mathrm{~mm}$ and then placed in a polyethylene bottle, followed by an addition of one liter acetic acid solution $(5.7 \mathrm{~mL}$ acetic acid in $1 \mathrm{~L}$ of distilled water, $\mathrm{pH}=2.88$ ). The bottle was placed in a rotary extractor and rotated for $18 \mathrm{~h}$ at $30 \pm 2 \mathrm{rpm}$. After rotation, the sample was filtered through a $0.45 \mu \mathrm{m}$ membrane filter, and then the filtrate was collected and analyzed for metal concentrations by using an atomic absorption spectrometer (Analytik Jena AG NovAA 400, Germany).

The schematic of the CLT is presented in Fig. S2. $\dagger$ As a dynamic test, CLT reportedly has a better leaching effect. ${ }^{28}$ Eighty grams of air-dried sludge specimens (Fenton-RM-II and RS-II) were grinded and sieved to achieve particle sizes smaller than $4 \mathrm{~mm}$, and placed in a glass column $(5 \mathrm{~cm}$ inside diameter and $35 \mathrm{~cm}$ height) and a perforated plate on both ends. The dewatered sludge was leached from the bottom up by a continuous flow of the acetic acid solution $(\mathrm{pH}=2.88)$ using a peristaltic pump. A flowing rate of $5 \mathrm{~mL} \mathrm{~h}^{-1}$, commonly used in literature, was adopted here; and a rate of $10 \mathrm{~mL} \mathrm{~h}^{-1}$ was also applied for a comparison.

The leachate was sampled at different liquid-to-solid ratios $\left(\mathrm{L} / \mathrm{S}, \mathrm{mL} \mathrm{g}^{-1}\right)$. $\mathrm{L}$ represents the volume of the acetic acid solution passed through the column, in $\mathrm{mL}$; and $\mathrm{S}$ represents the mass of the sludge sample in the column, in g. Heavy metals in the leachate were analyzed. The extraction percentage of each heavy metal is the mass ratio of heavy metal leached out to the total mass of heavy metal in the original sludge sample.

\subsection{Microstructural analysis}

Microstructural characteristics of the dewatered sludge samples were investigated by X-ray diffraction (XRD) and scanning electron microscopy (SEM). The specimens were immersed in ethanol to end the hydration reaction and then dried in an oven at $40{ }^{\circ} \mathrm{C}$ for $24 \mathrm{~h}$. XRD analyses were carried out using $\mathrm{Cu}$ $\mathrm{K} \alpha$ radiation, operated at $40 \mathrm{kV}$, with a scan speed of $0.2785^{\circ} \mathrm{s}^{-1}$ and in the $2 \theta$ range from $5^{\circ}$ to $75^{\circ}$. Morphology studies were carried out using a Sirion 200 scanning microscope after the samples were coated with gold.

\section{Results and discussion}

\subsection{Geotechnical properties of solidified sludge}

The geotechnical properties of the clay, RS-I and the dewatered sludge cakes are presented in Table 3. As shown, when compared to RS-I, the PL of the Fe-Lime-I decreased significantly from $58.1 \mathrm{wt} \%$ to $40.9 \mathrm{wt} \%$, while the PI increased from $11.6 \mathrm{wt} \%$ to $23.8 \mathrm{wt} \%$. As for the Fenton-RM-I, its PL and PI were $33.1 \mathrm{wt} \%$ and $35.4 \mathrm{wt} \%$, respectively. Moreover, the PL and PI of RS-PAM were close to those of RS. The changes can be seen more readily in Fig. 3. The LL values of the dewatered sludge cakes were nearly the same as that of the RS, but PL values of the dewatered sludge cakes were significantly less than that of the RS. Thus the PI values increased obviously from RS to the sludge cakes since PI equals to LL minus PL, as presented in Table 3. PI value was in the order of $\mathrm{RS}<\mathrm{Fe}$-Lime $<$ Fenton-RM. According to the classification of ASTM, the RS belongs to high-plasticity silty while the sludge cake of Fenton-RM is on the boundary of silty and clay. When compared to deep-dewatered sludge cakes (Fe-Lime and Fenton-RM), the standard clay has a smaller plasticity index values.

In addition, RS-I showed a high OMC of $37.5 \mathrm{wt} \%$ and an MDD of $1.581 \mathrm{~g} \mathrm{~cm}^{-3}$. While for both deep-dewatered sludge cakes, the values of OMC and MDD decreased considerably. It implied that deep-dewatered sludge cakes have lower waterabsorption capacity, when compared with RS and RS-PAM.

It can also be seen from Table 3 that the deep-dewatered sludge cakes had higher permeability coefficient values $\left(>10^{-7} \mathrm{~cm} \mathrm{~s}^{-1}\right)$ than that of RS $\left(6.45 \times 10^{-8} \mathrm{~cm} \mathrm{~s}^{-1}\right)$. These results validate the roles of skeleton builders in the conditioning stage that increased the porosity of dewatered sludge.

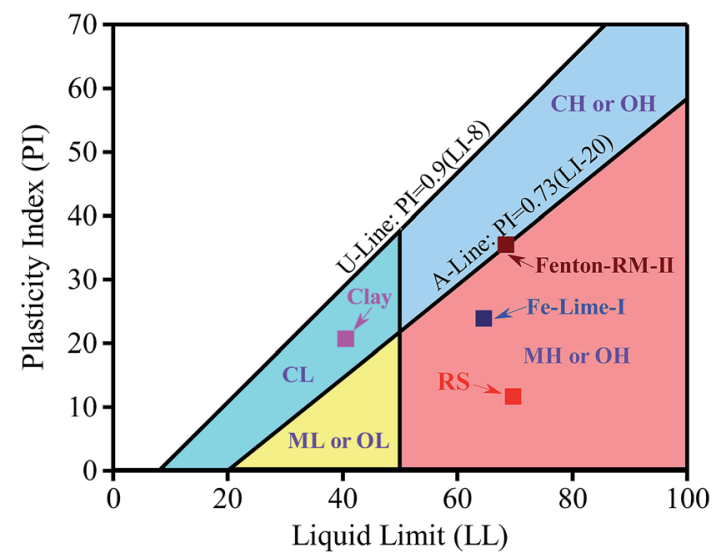

Fig. 3 Casagrande plasticity chart for clay, RS and the dewatered sludge cake (CL: low-plasticity clay; $\mathrm{CH}$ : high-plasticity clay; $\mathrm{ML}$ : lowplasticity silt; $\mathrm{OL}$ : low-plasticity organic; $\mathrm{MH}$ : high-plasticity silt; $\mathrm{OH}$ : high-plasticity organic. Accordance to ASTM D2487-93, 1997).

Table 3 Geotechnical properties of the sludge and other specimens

\begin{tabular}{|c|c|c|c|c|c|c|}
\hline Specimens & LL (wt\%) & PL (wt\%) & PI (wt\%) & OMC (wt\%) & $\begin{array}{l}\operatorname{MDD}(\mathrm{g} \\
\left.\mathrm{cm}^{-3}\right)\end{array}$ & $\begin{array}{l}\text { Coefficient of permeability } \\
\left(\mathrm{cm} \mathrm{s}^{-1}\right)\end{array}$ \\
\hline Clay & 40.6 & 20.0 & 20.6 & 12.4 & 1.890 & $3.31 \times 10^{-8}$ \\
\hline RS-I & 69.7 & 58.1 & 11.6 & 37.5 & 1.581 & $6.45 \times 10^{-8}$ \\
\hline RS-PAM & 69.3 & 59.8 & 9.5 & 36.9 & 1.561 & $6.71 \times 10^{-8}$ \\
\hline Fe-Lime-I & 64.7 & 40.9 & 23.8 & 25.5 & 1.421 & $5.90 \times 10^{-7}$ \\
\hline Fenton-RM-I & 68.5 & 33.1 & 35.4 & 23.0 & 1.435 & $7.20 \times 10^{-6}$ \\
\hline
\end{tabular}



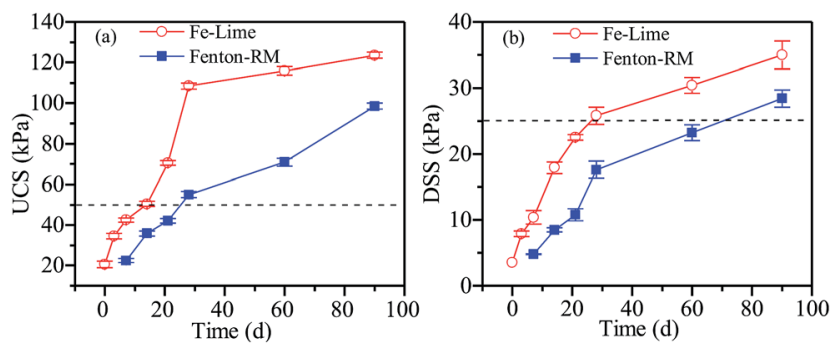

Fig. 4 (a) Unconfined compressive strength and (b) direct shear strength of the dewatered sludge cakes versus curing time. Dotted lines denote the minimum limits of Chinese standards for an effective landfill cover.

No existing Chinese standards define acceptable parameters with regards to the permeability coefficient of landfill cover. In USA, the permeability coefficients of lime-stabilized sludge as landfill cover range from $1 \times 10^{-3}$ to $10^{-6} \mathrm{~cm} \mathrm{~s}^{-1} \cdot{ }^{29}$ In general, the permeability coefficient values of the deep-dewatered sludge and the RS are less than the reported permeability coefficient values of lime-stabilized sludge. Both deep-dewatered sludge cakes had a permeability coefficient value (between $10^{-6}$ and $10^{-8} \mathrm{~cm} \mathrm{~s}^{-1}$ ), which is smaller to the reported permeability coefficient of the lime-stabilized sludge.

\subsection{Mechanical strength properties}

The relationship between the UCS and the curing age is shown in Fig. 4(a). As shown, the UCS values of the dewatered sludge cakes increase with the curing age. In general, a minimum UCS of $50 \mathrm{kPa}$ is the permissible limit in Chinese standard for an effective landfill cover material. ${ }^{12}$ It took 14 days and 28 days for the dewatered sludge of Fe-Lime and the Fenton-RM systems to go above this minimum limit, respectively. As shown in Fig. 4(b), the DSS values of the dewatered sludge cakes increase
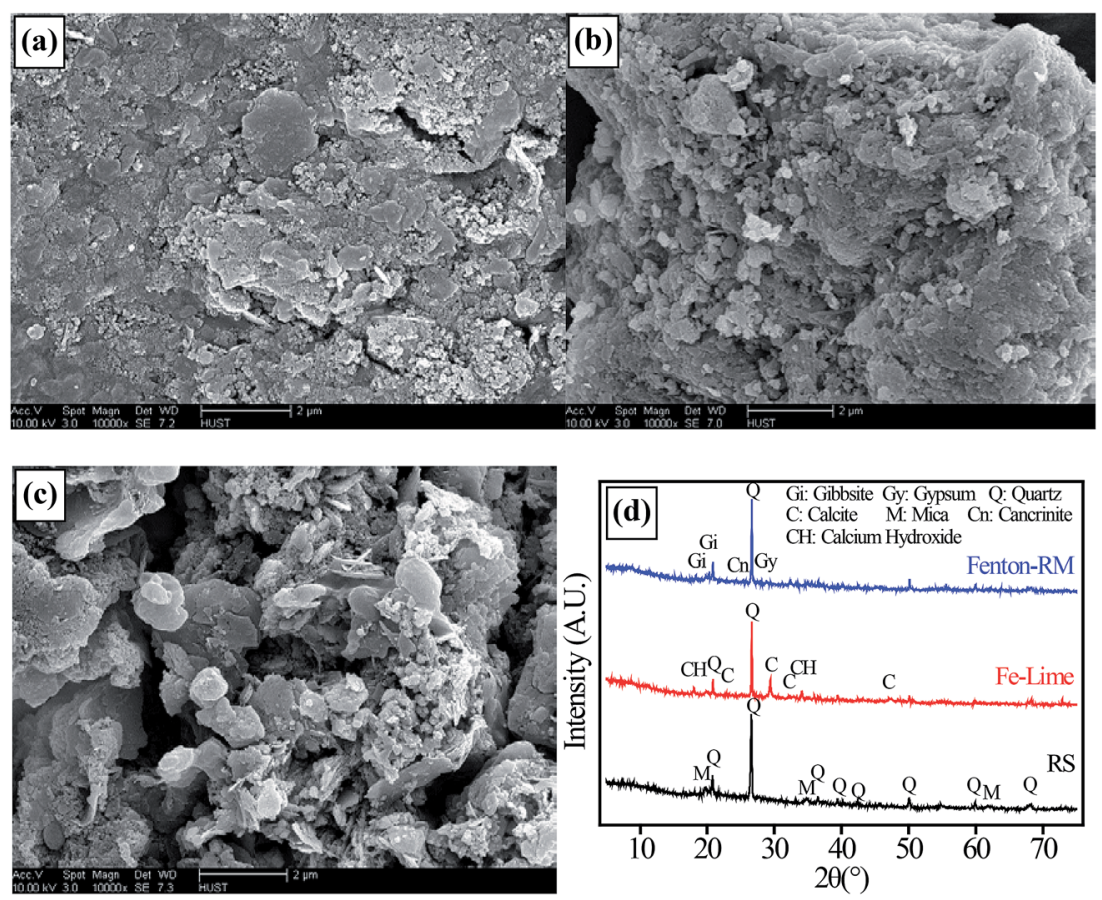

Fig. 5 SEM images of (a) RS-I, and the (b) dewatered sludge cakes of Fe-Lime-I, (c) Fenton-RM-I; and (d) the XRD patterns of these samples.
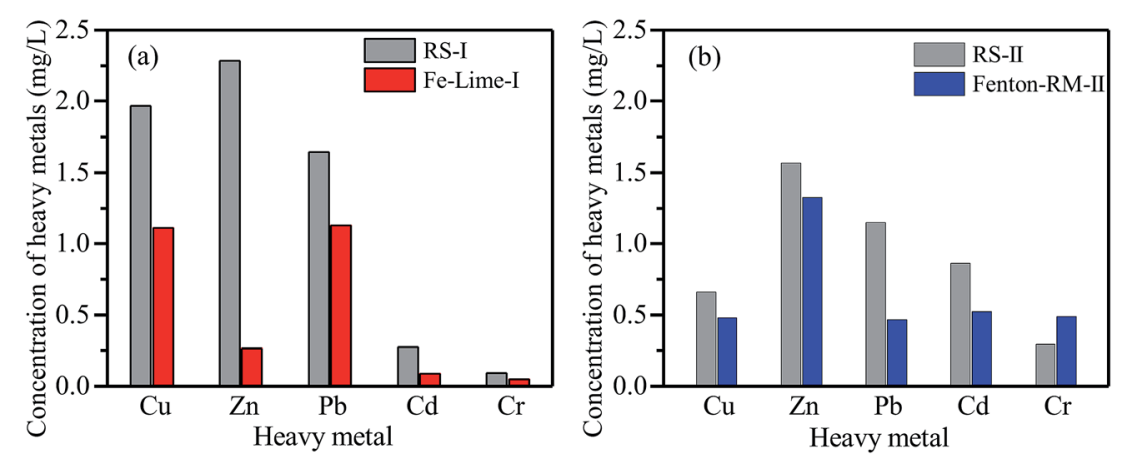

Fig. 6 Concentrations of heavy metal in the leachates from the TCLP tests: (a) RS-I, and Fe-Lime-I; (b) RS-II, and Fenton-RM-II. 
$\triangle$ RS-I $\boldsymbol{\Delta}$ Fe-Lime-I $\square$ RS-II $\boldsymbol{\square}$ Fenton-RM-II
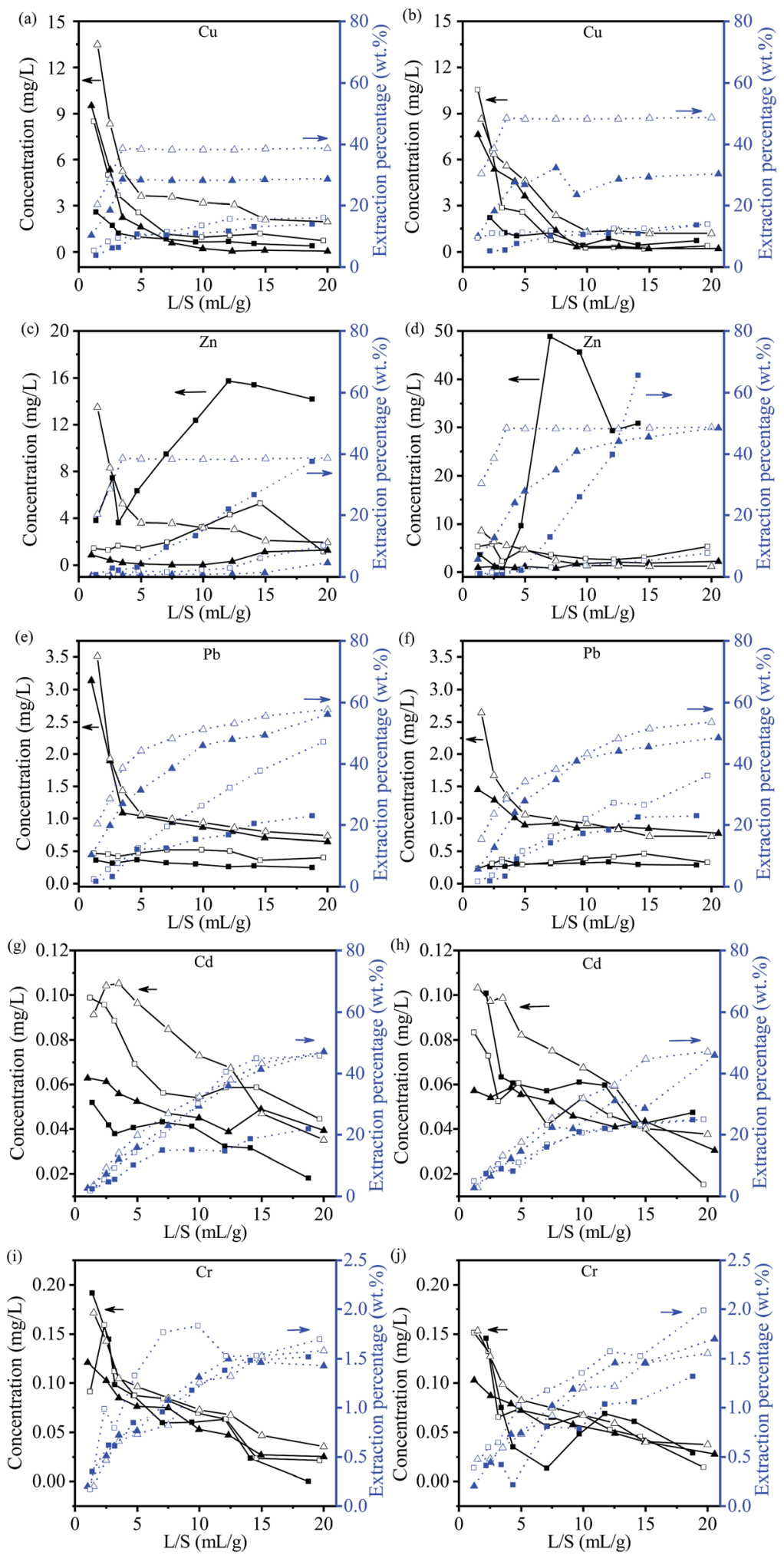

Fig. 7 Leached concentrations and extraction percentages of heavy metals from the column leaching tests: (a) $\mathrm{Cu}$, at a leaching rate of $5 \mathrm{~mL} \mathrm{~h}^{-1}$ and (b) $10 \mathrm{~mL} \mathrm{~h}^{-1}$; (c) $\mathrm{Zn}$, at a leaching rate of $5 \mathrm{~mL} \mathrm{~h}^{-1}$ and (d) $10 \mathrm{~mL} \mathrm{~h}^{-1}$; (e) Pb, at a leaching rate of $5 \mathrm{~mL} \mathrm{~h}^{-1}$ and (f) $10 \mathrm{~mL} \mathrm{~h}$; (g) Cd, at a leaching rate of $5 \mathrm{~mL} \mathrm{~h}^{-1}$ and (h) $10 \mathrm{~mL} \mathrm{~h}^{-1}$; (i) $\mathrm{Cr}$, at a leaching rate of $5 \mathrm{~mL} \mathrm{~h}^{-1}$ and (j) $10 \mathrm{~mL} \mathrm{~h}^{-1}$. 
with the curing age, which is consistent with the case for the UCS. In general, the required minimum limit of DSS for an effective landfill cover material is $25 \mathrm{kPa}$. It took 28 and 90 days for the dewatered sludge of Fe-Lime and Fenton-RM systems to go above this minimum limit, respectively. The results imply that lime could enhance the mechanical strengths of the dewatered sludge in Fe-Lime system more effectively than red mud (a skeleton builder in Fenton-RM system), and it took a shorter curing time for Fe-Lime system to attain the required mechanical strength.

\subsection{Microstructure characteristics}

Fig. 5 shows the SEM images and XRD patterns of the RS-I and the dewatered sludge cakes (Fe-Lime-I, and Fenton-RM-I). As shown in Fig. 5(a), the morphological structure of the RS is flake-like, dense and compact, since more organic matters in the RS filled most of voids in the dried RS specimen. The XRD pattern indicates that the RS consists mainly of quartz and mica. Microstructure characteristics of the RS are consistent with those found in the previous studies. ${ }^{\mathbf{2 0}, 21}$

The dewatered sludge cake of Fe-Lime-I consists of smaller particulates and it is more porous with an irregular shape (Fig. 5(b)). It indicates that the raw sludge with a high organic content and poor dewaterability can be improved with skeleton builders to generate a porous, but relatively incompressible structure. The XRD pattern indicates the $\mathrm{Fe}-$ Lime-I consists mainly of quartz, calcium hydroxide and calcite.

Some irregularly shaped crystals embedded among the sludge particles were found in Fenton-RM-I (Fig. 5(c)). This dewatered sludge cake appears to be more porous. The XRD patterns indicate that it consists mainly of quartz, mica, gypsum, cancrinite, and gibbsite.

\subsection{Leaching tests for heavy metals}

3.4.1 TCLP tests. Fig. 6 shows the heavy metals concentrations in the leachates of the TCLP tests for the RS and the deep-dewatered sludge cakes.

As shown in Fig. 6(a) and (b), leached concentrations of $\mathrm{Cu}$, $\mathrm{Zn}$ and $\mathrm{Pb}$ from the two dewatered sludge cakes of Fe-Lime-I are significantly lower than those of the RS-I; while Cr concentration in the dewatered sludge of Fenton-RM-II are the highest among all of RS and dewatered sludge specimens (Fig. 6(b)). The higher concentrations of $\mathrm{Cr}$ might come from the red mud which was added as the conditioner. In general, the sludge cake from the Fe-Lime system has a good retention for heavy metals.

Typical acceptable TCLP concentrations of heavy metals effluent discharge standards of municipal solid waste landfills are $40,100,0.25,0.15$ and $4.5 \mathrm{mg} \mathrm{L}^{-1}$ of $\mathrm{Cu}, \mathrm{Zn}, \mathrm{Pb}, \mathrm{Cd}$, and $\mathrm{Cr}$ (GB16889-2008), respectively. ${ }^{30}$ The results show that $\mathrm{Pb}$ in $\mathrm{Fe}-$ Lime-I exceeded the acceptable limit, while the retention capability of Fenton-RM-II on $\mathrm{Pb}$ and $\mathrm{Cd}$ needs to be improved. In order to facilitate technology adaptability, two improvements could be used to promote the solidification effects of the dewatered sludge cakes. Firstly, during the conditioning and dewatering process, a little more dosage of conditioner (lime or cement) could be added to further improve the dewatering effects and the heavy metal solidification behavior. Besides, to avoid the risk of heavy metal release in the landfill process, small amount of cement could be mixed with the dewatered sludge cakes to strengthen the heavy metal solidification effects, given the good cooperation of alkali cement and red mud.

3.4.2 Column leaching test (CLT). Plots of leached concentrations and extraction percentages of various heavy metals versus the L/S ratios from the CLTs are shown in Fig. 7. In general, the leached concentrations of all heavy metals declined and the extraction percentages increased with an increase in the $\mathrm{L} / \mathrm{S}$ ratio (i.e., age of landfill cover). In addition, at the same $\mathrm{L} / \mathrm{S}$ ratio, more heavy metals were expectedly leached out at a low leaching rate of $5 \mathrm{~mL} \mathrm{~h}^{-1}$ than at $10 \mathrm{~mL} \mathrm{~h}^{-1}$, because of the longer contact time. The extraction percentage of $\mathrm{Cu}$ from the Fe-Lime-I was lower than that of the RS-I; while the extraction percentage of $\mathrm{Cu}$ from Fenton-RM-II is the lowest $(<20 \mathrm{wt} \%)$. The results of CLT are consistent with those of the TCLP experiments. The leaching characteristics of $\mathrm{Zn}$ are essentially the same as those of $\mathrm{Cu}$ in all four samples. However, the leached concentration of $\mathrm{Zn}$ from Fenton-RM-II increased significantly with time. The reason might be that the concentration of $\mathrm{Zn}$ in RS-II was much higher than that of RS-I. The leached concentrations of $\mathrm{Pb}$ and $\mathrm{Cd}$ from Fe-Lime-I are essentially the same as those of the RS-I; while addition of RM appears to have a better retention of $\mathrm{Pb}$ and $\mathrm{Cd}$ as their extraction percentages from Fenton-RM-II were less than 30 $\mathrm{wt} \%$. For the case of $\mathrm{Cr}$, nearly $30 \mathrm{wt} \%$ of $\mathrm{Cr}$ was leached out from the RM, the extraction percentages of $\mathrm{Cr}$ in all the dewatered sludge samples were at a low level ( $<2 \mathrm{wt} \%)$.

The results of this CLT study indicate that the deepdewatered sludge cakes conditioned with skeleton builders are relative stable for a long period of time, with regards to heavy metal leaching, when they are used as daily or final landfill cover.

\section{Conclusion}

In this study, feasibility of reusing deep-dewatered sludge cakes without addition of solidifying agents as landfill cover materials was evaluated. Results of geotechnical tests indicate that deepdewatered sludge cakes, conditioned with skeleton builders, improved the geotechnical properties of the dewatered sludge, when compared with RS and RS-PAM. The deep-dewatered sludge cakes can attain the required USC and DSS needed for landfill covers within a short curing time. The XRD patterns and SEM images validated the framework effect of the skeleton builders and showed that these cakes are less compressible. Results of leaching tests using both TCLP and CLT revealed that both deep-dewatered sludge cakes could retain heavy metals for a long period of time.

In summary, the skeleton builders introduced in the conditioning stage during deep-dewatering process improve the geotechnical properties and heavy metal leaching characteristics of the dewatered sludge cakes which make them appropriate for re-use as landfill cover materials. 


\section{Abbreviation}

$\begin{array}{ll}\text { CLT } & \text { Column leaching test } \\ \text { DS } & \text { Dry solid } \\ \text { DSS } & \text { Direct shear strength } \\ \text { LL } & \text { Liquid limit } \\ \text { L/S } & \text { Liquid-to-solid ratio } \\ \text { MDD } & \text { Maximum dry density } \\ \text { OMC } & \text { Optimum moisture content } \\ \text { PAM } & \text { Polyacrylamide } \\ \text { PI } & \text { Plasticity index } \\ \text { PL } & \text { Plastic limit } \\ \text { RM } & \text { Red mud } \\ \text { RS } & \text { Raw sludge } \\ \text { SEM } & \text { Scanning electron microscopy } \\ \text { TCLP } & \text { Toxicity characteristic leaching procedure } \\ \text { TSS } & \text { Total suspended solids } \\ \text { UCS } & \text { Unconfined compressive strength } \\ \text { VSS } & \text { Volatile suspended solids } \\ \text { WWTP } & \text { Wastewater treatment plant } \\ \text { XRD } & \text { X-ray diffraction }\end{array}$

\section{Acknowledgements}

The research was supported by the National Natural Science Foundation of China (51508214), the Research Project of Chinese Ministry of Education (113046A), Project of Innovative and Interdisciplinary Team of Huazhong University of Science and Technology (2015ZDTD027) and the Foundation of State Key Laboratory of Coal Combustion (FSKLCCA1604). The authors would like to thank Analytical and Testing Center of Huazhong University of Science and Technology for providing detecting instruments.

\section{References}

1 G. Zhen, X. Yan, H. Zhou, H. Chen, T. Zhao and Y. Zhao, J. Environ. Sci., 2011, 23, 1225-1232.

2 L. Jin, G. Zhang and H. Tian, Water Res., 2014, 66, 85-98.

3 U. S. EPA, 40 CFR Part 257, 1993.

4 E. H. Kim, J. K. Cho and S. Yim, Chemosphere, 2005, 59, 387-395.

5 H. Liu, P. Liu, H. Hu, Q. Zhang, Z. Wu, J. Yang and H. Yao, Chemosphere, 2014, 117, 559-566.

6 S. Valls and E. Vàzquez, Cem. Concr. Res., 2000, 30, 1671-1678.

7 V. Bednarik, M. Vondruska, M. Sild and K. Marek, J. Environ. Eng., 2004, 130, 1527-1533.
8 E.-H. Kim, J.-K. Cho and S. Yim, Chemosphere, 2005, 59, 387395.

9 P. Samaras, C. A. Papadimitriou, I. Haritou and A. I. Zouboulis, J. Hazard. Mater., 2008, 154, 1052-1059.

10 M. Jianli, Z. Youcai, W. Jinmei and W. Li, Constr. Build. Mater., 2010, 24, 79-83.

11 Y. L. Li, J. W. Liu, J. Y. Chen, Y. F. Shi, W. Mao, H. Liu, Y. Li, S. He and J. K. Yang, Int. J. Environ. Sci. Technol., 2014, 11, 233-240.

12 Standardization Administration of the People's Republic of China, GB/T 23485-2009, 2009.

13 G. Zhang, J. He, P. Zhang and J. Zhang, J. Hazard. Mater., 2009, 164, 1105-1109.

14 K. Hu, J. Q. Jiang, Q. L. Zhao, D. J. Lee, K. Wang and W. Qiu, Water Res., 2011, 45, 5969-5976.

15 K. Song, X. Zhou, Y. Liu, G.-J. Xie, D. Wang, T. Zhang, C. Liu, P. Liu, B. Zhou and Q. Wang, Chem. Eng. J., 2016, 295, 436442.

16 H. Liu, S. Yang, J. Shi, X. Xu, H. Liu and B. Fu, Sep. Purif. Technol., 2016, 165, 53-59.

17 U. S. EPA, EPA-625/1-82/014, 1987.

18 S. Deneux-Mustin, B. S. Lartiges, G. Villemin, F. Thomas, J. Yvon, J. L. Bersillon and D. Snidaro, Water Res., 2001, 35, 3018-3024.

19 Y. Qi, K. B. Thapa and A. F. Hoadley, Chem. Eng. J., 2011, 171, 373-384.

20 H. Liu, J. Yang, N. Zhu, H. Zhang, Y. Li, S. He, C. Yang and H. Yao, J. Hazard. Mater., 2013, 258, 144-150.

21 H. Zhang, J. Yang, W. Yu, S. Luo, L. Peng, X. Shen, Y. Shi, S. Zhang, J. Song, N. Ye, Y. Li, C. Yang and S. Liang, Water Res., 2014, 59, 239-247.

22 C. Li, S. Zhang, J. Yang, Y. Shi, W. Yu, S. Liang, J. Song, Q. Xu, Y. Chen, J. Hu, Y. Li and C. Yang, RSC Adv., 2015, 5, 102332102339.

23 H. Liu, Y. Li, Y. Shi, Y. Li, S. He and J. Yang, Environ. Chem., 2011, 30, 1877-1882.

24 Ministry of Construction of the People's Republic of China, GB/T 50123-1999, 1999.

25 ASTM, D2487-93, 1997.

26 Ministry of Transport of the People's Republic of China, JTG E40-2007, 2007.

27 U. S. EPA, Test method 1311, 1996.

28 NEN 7343, Netherlands Standardisation Institute, 1995.

29 A. Jacobs and M. Silver, Water Sci. Technol., 1990, 22, 93-106.

30 Ministry of Environmental Protection of the People's Republic of China, GB 16889-2008, 2008. 